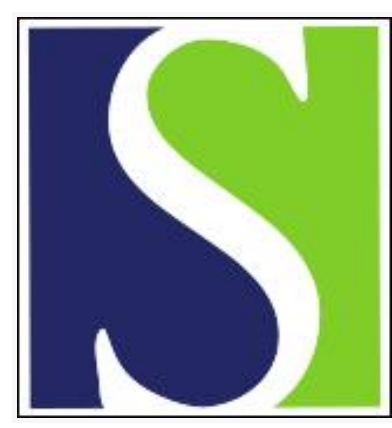

Scand J Work Environ Health 1997;23(6):458-461

https://doi.org/10.5271/sjweh.269

Issue date: Dec 1997

\title{
Cancer incidence of sulfite pulp workers in Denmark
}

by Rix BA, Villadsen E, Lynge E

The following articles refer to this text: 2001;27(2):113-119;

2002;28(5):333-340

Key terms: neoplasm; occupational exposure; pancreas; stomach

This article in PubMed: www.ncbi.nlm.nih.gov/pubmed/9476810

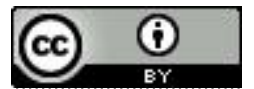




\title{
Cancer incidence of sulfite pulp workers in Denmark
}

\author{
by Bo A Rix, MD, ${ }^{1}$ Ebbe Villadsen, ${ }^{1}$ Elsebeth Lynge, $P h D^{1}$
}

\begin{abstract}
Rix BA, Villadsen E, Lynge E. Cancer incidence of sulfite pulp workers in Denmark. Scand J Work Environ Health 1997;23(5):458-61.

Objectives Studies have indicated an excess risk of stomach cancer, pancreas cancer, and non-Hodgkin's lymphoma for sulfite pulp mill workers, and therefore cancer incidence was evaluated for 2 Danish sulfite mills. Methods Altogether 2238 workers employed in 1955-1990 were included in a historic cohort and followed until 31 December 1993. National cancer rates were used to calculate the expected number of cancer cases.

Results The overall cancer risk was close to the expected, the standardized incidence ratio (SIR) being 1.01. The risk of stomach cancer was doubled [10 observed, SIR 1.99, 95\% confidence interval (95\% CI) 0.95-3.66], as was the risk of pancreatic cancer ( 7 observed, SIR $1.88,95 \%$ CI $0.75-3.88$ ). For the men with known pulp exposure, lung cancer was slightly increased (SIR $1.53,95 \%$ CI $0.94-2.37$ ). Other cancers with elevated risks were leukemia ( 7 observed, SIR 1.84) and soft-tissue sarcomas (4 observed, SIR 2.37). The risk of nonHodgkin's lymphoma was not increased.

Conclusions The excess risk of stomach cancer and pancreatic cancer found in this study was in accordance with that of other studies from sulfite pulp mills.
\end{abstract}

Key terms neoplasms, occupational exposure, pancreas, stomach.

Cellulose fibers for paper production come from pulped wood (1). The most widely used method of pulping is the alkaline sulfate process, or Kraft process, which can be used for most kinds of wood and which allows for rather easy recovery of the chemicals used (1). Only a minority of pulp mills use the older acidic or sulfite process, which is applicable to low-resin woods and, in some instances, also the pulping of straw. In sulfate and sulfite pulp mills it is common to bleach the cellulose so that the paper will be suitable for printing, and chlorine has been widely used in the bleaching processes (2). A variety of chlorinated organic compounds has been found in pulp and sludge from pulp mills, for example, 2,3,7,8-tetrachlorodibenzo- $p$-dioxin, other dioxins, polychlorinated dibenzofurans, and other chlorinated organic compounds $(2-5)$.

Studies in pulp and paper mills have indicated excess risks of stomach cancer, pancreas cancer, and non-Hodgkin's lymphomas among sulfite mill workers (6). Studies among workers exposed to chlorinated organic compounds have indicated an increased risk for soft-tissue sarcomas (7). As 2 sulfite pulp mills have operated in Denmark for many years and all cancer cases are registered in a compulsory national cancer register, we conducted a historical cohort study of cancer risk in the Danish sulfite pulp industry.

\section{Materials and methods}

One sulfite pulp mill started production in 1955 and the other in 1962. The oldest plant produces cellulose from straw, and chlorine is used to bleach the pulp. The other plant produces neutral semichemical sulfite pulp from hard wood, and no pulp bleaching takes place. The management of both plants supplied information about former and current employees on a diskette, including name, personal identification number or birthday, date of employment or retirement, department of work, and job title. Data on 1143 persons were obtained from the oldest plant by 25 February 1992 , along with data on 570 persons from the other plant. In order to make the cohort as complete as possible, information on former employees was also retrieved from a national supplementary pension scheme, called ATP, which was established in 1964. From the pension scheme, 525 additional persons not reported from the plants were included, and the total cohort thus included 2238 persons, only 102 being women. Sixty-five percent of the workers had been employed for less than 1 year, $21 \%$ between 1 and 5 years, and $14 \%$ for more than 5 years.

From 1 April 1968 on, all Danish citizens have been given a unique personal identification number, and all dates of deaths, emigrations and disappearances have

1 Danish Cancer Society, Copenhagen, Denmark.

Reprint requests to: Dr Bo Rix, Danish Cancer Society, Strandboulevarden 49, DK-2100 Copenhagen, Denmark. 
been recorded in the Central Population Register. On 22 February 1996 the Central Population Register was searched for members of the cohort with a personal identification number for vital status. The National Mortality Register was searched for the date of death of members of the cohort without a personal identification number. Following these procedures, a total of 2198 persons out of the 2238 persons in the cohort were identified (98\%). For each person, the person-years at risk were calculated from the start of employment until death, emigration, disappearance, or the end of follow-up on 31 December 1993, whichever came first.

The Danish Cancer Register started in 1943. In the years 1943-1977, reported cancer cases were coded according to a modified version of the seventh revision of the International Classification of diseases (ICD-7). From 1978 on, reported cancer cases have been coded according to ICD-O and automatically converted to ICD7 codes. For members of the Danish pulp mill cohort without a personal identification number, notified cancer cases were searched for manually from lists of cancer patients with equivalent gender and date of birth in the cancer register. The Cancer Register was searched on 1 June 1996 for members with a personal identification number. All tumors diagnosed in the individual risk periods were included. Using the PYRS program (8), we calculated the expected numbers of cancer cases from the person-years at risk and the cancer incidence rates for the total Danish population for gender, 5-year age groups, and calendar periods $(1943-1947,1948-1952, \ldots$.
1988 - 1992) The rates for 1988 - 1992 were used to calculate the expected numbers for 1993. The standardized incidence ratios (SIR) were calculated by dividing the observed number of cancer cases in a given group by the expected number, and the $95 \%$ confidence intervals (95\% CI) were calculated using Byar's approximation (9).

\section{Results}

The cancer risk for all male workers is shown in table 1 . Female workers were not included in the table as their number of cancer cases was small. The overall cancer risk was as expected for the men (141 observed cases, SIR $1.01,95 \%$ CI $0.85-1.19)$ and slightly increased for the women ( 6 observed, SIR $1.32,95 \%$ CI $0.48-2.88$ ). The risk of stomach cancer was doubled for the men (10 observed, SIR $1.99,95 \%$ CI $0.95-3.66)$ as was the risk of pancreatic cancer ( 7 observed, SIR $1.88,95 \%$ CI $0.75-3.88$ ). The lung cancer incidence was also slightly in excess for the men in the cohort (33 observed cases, SIR 1.33, 95\% CI 0.92-1.87). Finally, leukemia risk was increased for the men, on the basis of 7 cases (SIR $1.84,95 \%$ CI $0.74-3.80$ ). The 3 cases of non-Hodgkin's lymphoma among the men was close to the expected number.

Since 1943 the coding of Danish cancer cases by morphology and topography has made it possible to tabulate the observed and expected numbers of soft-tissue sarcomas, including those located in different organs,

Table 1. Observed $(0)$ and expected $(E)$ number of cancer cases for all Danish male workers and for all male workers in the Danish sulfite pulp industry by diagnostic group. (SIR = standardized incidence ratio, $95 \% \mathrm{Cl}=95 \%$ confidence interval)

\begin{tabular}{|c|c|c|c|c|c|c|c|c|}
\hline \multirow[t]{2}{*}{ Diagnosisa } & \multicolumn{4}{|c|}{ All male workers } & \multicolumn{4}{|c|}{ Male workers in sulfite pulping } \\
\hline & 0 & $E$ & SIR & $95 \% \mathrm{Cl}$ & 0 & $E$ & SIR & $95 \% \mathrm{Cl}$ \\
\hline All cancer $(104-205)$ & 141 & 140.20 & 1.01 & $0.85-1.19$ & 75 & 71.99 & 1.04 & $0.82-1.31$ \\
\hline Buccal cavity (140-144) & 3 & 3.52 & 0.85 & $0.17-2.49$ & 3 & 1.85 & 1.62 & $0.33-4.74$ \\
\hline Pharynx (145-148) & - & 1.27 & $\cdot$. &. & - & 0.66 & .' & ." \\
\hline Esophagus (150) & - & 1.78 &.. &.. & - & 0.94 & $\cdot \cdot$ & \\
\hline Stomach $(151)$ & 10 & 5.03 & 1.99 & $0.95-3.66$ & 4 & 2.60 & 1.54 & $0.41-3.94$ \\
\hline Colon (153) & 6 & 8.71 & 0.69 & $0.25-1.50$ & 3 & 4.49 & 0.67 & $0.13-1.95$ \\
\hline Rectum (154) & 8 & 6.71 & 1.19 & $0.51-2.35$ & 5 & 3.50 & 1.43 & $0.46-3.33$ \\
\hline Liver, primary (155) & 1 & 1,39 & 0.72 & $0.01-4.00$ & 1 & 0.73 & 1.37 & $0.02-7.62$ \\
\hline Gall bladder (155.1) & 1 & 0.79 & 1.27 & $0.02-7.04$ & - & 0.40 & $\ddot{0}$ & ." \\
\hline Pancreas (157) & 7 & 3.72 & 1.88 & $0.75-3.88$ & 4 & 1.93 & 2.07 & $0.56-5.31$ \\
\hline Larynx (161) & 2 & 2.68 & 0.75 & $0.08-2.69$ & 2 & 1.43 & 1.40 & $0.16-5.05$ \\
\hline Lung (162) & 33 & 24.79 & 1.33 & $0.92-1.87$ & 20 & 13.05 & 1.53 & $0.94-2.37$ \\
\hline Prostate (177) & 7 & 9.64 & 0.73 & $0.29-1.50$ & 1 & 4.89 & 0.20 & $0.00-1.14$ \\
\hline Testis (178) & 6 & 5.21 & 1.15 & $0.42-2.51$ & 2 & 2.28 & 0.88 & $0.10-3.17$ \\
\hline Kidney (180) & 4 & 4.58 & 0.87 & $0.23-2.24$ & 4 & 2.40 & 1.67 & $0.45-4.27$ \\
\hline Bladder (181) & 9 & 11.52 & 0.78 & $0.36-1.48$ & 3 & 6.02 & 0.50 & $0.10-1.46$ \\
\hline Melanoma of skin (190) & 3 & 4.13 & 0.73 & $0.15-2.12$ & 1 & 2.04 & 0.49 & $0.01-2.73$ \\
\hline Skin, other (191) & 16 & 19.85 & 0.81 & $0.46-1.31$ & 8 & 10.22 & 0.78 & $0.34-1.54$ \\
\hline Brain (193) & 2 & 5.37 & 0.37 & $0.04-1.34$ & 1 & 2.68 & 0.37 & $0.00-2.08$ \\
\hline Bone (196) & - & 0.33 & .. & 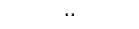 & - & 0.16 &.. &.$\cdot$ \\
\hline Connective tissue (197) & 1 & 0.68 & 1.47 & $0.02-8.18$ & 1 & 0.33 & 3.03 & $0.04-16.86$ \\
\hline Non-Hodgkin's lymphoma $(200,202)$ & 3 & 3.67 & 0.82 & $0.16-2.39$ & 2 & 1.84 & 1.09 & $0.12-3.92$ \\
\hline Hodgkin's disease (201) & 2 & 1.52 & 1.32 & $0.15-4.75$ & 1 & 0.71 & 1.41 & $0.02-7.84$ \\
\hline Leukemia (204) & 7 & 3.80 & 1.84 & $0.74-3.80$ & 5 & 1.93 & 2.59 & $0.83-6.05$ \\
\hline
\end{tabular}

a Code of the International Classification of Diseases, seventh revision, in parentheses. 
and 4 soft-tissue sarcomas were observed among the men versus 1.69 expected (SIR 2.37, 95\% CI 0.64 6.06).

When the analysis was restricted to the men known to have worked primarily in the sulfite pulping area of the mills, a total of 75 cancer cases was observed (SIR $1.04,95 \%$ CI $0.82-1.31$ ). The stomach cancer risk was less increased than in the total cohort ( 4 observed, SIR $1.54,95 \%$ CI $0.41-3.94$ ), while the pancreatic cancer risk was more than doubled (4 observed, SIR 2.07, 95\% $0.56-5.31)$. The lung cancer incidence was slightly higher (20 observed, SIR $1.53,95 \%$ CI $0.94-2.37$ ) than that of the total cohort, as was the leukemia risk ( 5 observed, SIR 2.59, 95\% CI 0.83-6.05). Other cancer sites with an excess risk in this subcohort were buccal cavity ( 3 observed, SIR 1.62), rectum (5 observed, SIR 1.43), and kidney (4 observed, SIR 1.67). Among the men in the sulfite pulping area, 3 soft-tissue sarcomas were observed (SIR 3.66, 95\% CI 0.74-10.69).

An analysis by latency time and length of employment for the cancer sites of interest showed no specific trend due to the small number of cancer cases.

\section{Discussion}

The overall cancer risk in this cohort of Danish sulfite pulp mill workers was the same as that of the national population. This finding agrees with the results of 3 other cohort studies of cancer risk in sulfite pulp mill workers in Finland (10) and the United States $(11,12)$.

The Danish cohort had a 2 -fold stomach cancer risk. The stomach cancer risk was also increased among workers in American sulfite mills (11), 11 cases (standardized mortality ratio 149) with an increasing risk by time since first employment, but not by duration of employment. The stomach cancer risk was, however, only moderately increased (10) or lower than expected (12) in the 2 other sulfite mill cohorts. A Swedish case-referent study (13) indicated a statistically significant excess risk of stomach cancer among sulfite pulp workers (odds ratio 2.8), as did a proportionate mortality study among sulfite pulp mill workers in the United States and Canada (14). Sulfur dioxide is commonly measured in sulfite mills (15), but the evidence for the carcinogenicity of sulfur dioxide and sulfites is inadequate (16). It has been suggested that exposure to wood dust may explain the excess risk of stomach cancer among pulp workers (11), but only 1 of the Danish sulfite pulp mills used wood as raw material, and the excess stomach cancer risk was found in both plants. Socioeconomic factors may also be involved (6), as the mill workers may have been recruited from neighboring rural areas.

Pancreatic cancer risk was doubled among the Danish men employed in the sulfite pulping area. The risk of pancreas cancer was tripled (standardized mortality ratio
305), a finding based on 5 cases, in an American cohort study of sulfite pulp workers (12), but the risk was only one-third the expected number in another cohort of male sulfite workers (11). Proportionate mortality studies have found pancreas cancer mortality to be moderately higher than expected for sulfite workers [proportionate mortality ratio $141(14)]$ and for pulp and paper workers in general [proportionate mortality ratio 126 (17)]. Two case-referent studies based on death certificates also indicated an excess risk of pancreatic cancer in the paper industry [odds ratios of 1.77 (18) and 1.40 (19)]. Pancreatic cancer is related to tobacco smoking (20). No smoking information was available on individual workers in this study.

For the men employed in the sulfite pulping area, the lung cancer risk was about $50 \%$ higher than expected from national rates. In 3 other sulfite pulp cohorts, the lung cancer risk was not increased (10-12), and a proportionate mortality study showed no excess lung cancer risk for sulfite mill workers (14). Again, smoking, or possibly asbestos used as insulation in the industry, cannot be ruled out as a confounding factor.

This Danish study showed a doubled leukemia risk, the highest risk occurring for men employed in the sulfite pulping area of the mills. However, none of the other cohort studies in sulfite mills have shown an excess risk for leukemia (10-12). The leukemia risk was moderately increased among sulfite mill workers in one proportionate mortality study (proportionate mortality ratio 1.32) (14), and some studies have indicated an excess leukemia risk in the pulp and paper industry in general $(21-23)$.

The finding of an excess risk for soft-tissue sarcomas in the Danish sulfite mill cohort is interesting. Soft-tissue sarcomas have been related to exposure to chlorinated compounds such as phenoxy herbicides, chlorophenols, and dioxins in the workplace (7), and chlorinated organic compounds have been found in the pulp and paper industry (3). However, chlorinated organic compounds are created when chlorine and chlorinated compounds are used in the bleaching of pulp, and 3 of the 4 persons with soft-tissue sarcomas in the Danish cohort had been employed in the mill where no pulp bleaching took place. Thus the finding in this study may be due to chance.

In conclusion, this study of workers in the sulfite pulp industry indicated an excess risk of stomach cancer and pancreatic cancer, and this excess agrees with the findings of other studies in the industry.

\section{Acknowledgments}

This study was supported by grants $91-7590$ and 93 7627 from the Danish Cancer Society.

Torsten Skov participated in the initial phase of the data collection. 


\section{References}

1. International Agency for Research on Cancer (IARC). Wood leather and some associated industries. Lyon: IARC, 1981. IARC monographs on the evaluation of the carcinogenic risk of chemicals to humans, vol 25.

2. Rappe C. Environmental stable chlorinated contaminants from the pulp and paper industry. In: Vainio $\mathrm{H}$, Sorsa $\mathrm{M}, \mathrm{Mc}$ Michael AJ, editors. Complex mixtures and cancer risk. Lyon: International Agency for Research on Cancer (IARC), 1990:341-53. IARC scientific publications, vol 104.

3. Vainio H, Hesso A, Jäppinen P. Chlorinated dioxins and dibenzofurans in the environment - a hazard to public health. Scand J Work Environ Health 1989;15:377-82.

4. Neilson AH, Allard A-S, Hynning P- $\AA$, Remberger M, Viktor $T$. The environmental fate of chlorophenolic constituents of bleachery effluents. Tappi J 1990; March:239_. 47 .

5. Fiedler $\mathbf{H}$, Hutzinger $O$. Dioxins: sources of environmenta load and human exposure. Toxicol Environ Chem 1990;29:157-234.

6. Torén K, Persson B, Wingren G. Health effects of working in pulp and paper mills: malignant diseases. Am J Ind Med 1996; 29:123-30.

7. Kogevinas M, Kauppinen T, Winkelmann R, Becher H, Bertazzi PA, Bueno de Mesquita HB, et al. Soft tissue sarcoma and non-Hodgkin's lymphoma in workers exposed to phenoxy herbicides, chlorophenols and dioxins: two nested case-control studies. Epidemiology 1995;6:396-402.

8. Coleman M, Douglas A, Hermon C, Peto J. Cohort study analysis with a Fortran computer program. Int $\mathbf{J}$ Epidemiol $1986 ; 15: 134-7$

9. Breslow NE, Day NE. Statistical methods in cancer research, vol II. Lyon: International Agency for Research on Cancer 1987.

10. Jäppinen P, Hakulinen T, Pukkala E, Tola S, Kurppa K. Cancer incidence of workers in the Finnish pulp and paper industry. Scand J Work Environ Health 1987;13:197-202.

11. Robinson CF, Waxweiler RJ, Fowler DP. Mortality among production workers in pulp and paper mills. Scand J Work Environ Health 1986;12:552-60.
12. Henneberger PK, Ferris JR BG, Monson RR. Mortality among pulp and paper workers in Berlin, New Hampshire. Br J Ind Med 1989;46:658-64

13. Wingren $\mathrm{G}$, Kling $\mathrm{H}$, Axelson $\mathrm{O}$. Gastric cancer among paper mill workers. J Occup Med 1985;27:715.

14. Milham S, Demers RY, Mortality among pulp and paper workers. J Occup Med 1984;26:844-6.

15. Kangas J, Jäppinen $P$, Savolainen $H$. Exposure to hydrogen sulfide, mercaptans and sulfur dioxide in pulp industry. Am Ind Hyg Assoc J 1984;45:787-90.

16. International Agency for Research on Cancer (IARC). Occupational exposures to mists and vapours from strong inorganic acids; and other industrial chemicals. Lyon: IARC, 1992. IARC monographs on the evaluation of the carcinogenic risk of chemicals to humans, vol 54.

17. Schwartz E. A proportionate mortality ratio analysis of pulp and paper mill workers in New Hampshire. Br J Ind Med $1988 ; 45: 234-8$.

18. Pickle LW, Gottlieb MS. Pancreatic cancer mortality in Louisiana. Am J Public Health 1980;70:256-9.

19. Wingren G, Persson B, Thorén K, Axelson O. Mortality pattern among pulp and paper mill workers in Sweden: a casereferent study. Am J Ind Med 1991;20:769-74.

20. International Agency for Research on Cancer (IARC). Tobacco smoking. Lyon: IARC, 1986. IARC monographs on the evaluation of the carcinogenic risk of chemicals to humans, vol 38 .

21. Milham S. Occupational mortality in Washington state 1950 79. Cincinnati $(\mathrm{OH})$ : US Department of Health and Human Services, 1993

22. Solet D, Zoloth SR, Sullivan C, Jewett J, Michaels DM. Patterns of mortality in pulp and paper workers. J Occup Med 1989;31:627-30.

23. Schwartz E. A proportionate mortality ratio analysis of pulp and paper mill workers in New Hampshire. $\mathrm{Br} \mathrm{J}$ Ind Med $1988 ; 45: 234-8$

Received for publication: 15 January 1997 